\title{
A NOVEL ANALYSIS OF NON-LINEAR TRANSFORMATION OF RANDOM SIGNALS AND ITS APPLICATION TO THE AMPLITUDE LIMITER
}

\section{GLOSS ARY OF SYMBOLS}

\author{
$x(t)$ - random process \\ $s(t)$ - useful signal \\ $n(t), n^{\prime}(t)$ - noise \\ $w_{1}(x, t), \varphi_{1}(x, t)$ - single-argument probability density distri- \\ bution of instantaneous values of $x(t)$ \\ $E_{k} x(t)$ - initial $k$-th moment of the process $x(t)$ \\ $R_{x}\left(t_{1}, t_{2}\right), R_{x}(\tau)$ - correlation function of the process $x(t)$ \\ $G_{x}(\omega)$ - spectral power density of the process $x(t)$ \\ $K(i \omega)$ - transfer function of the linear system \\ $g[x(t)]$ - characteristic of the non-linear system
}

\section{INTRODUCTION}

The object of the present paper is to determine the power of the useful signal $S_{0}$, the power of the noise $N_{0}$, the ratio $S_{0} / N_{0}$ and what is referred to as a coefficient of improvement $\left(S_{0} / N_{0}\right) /\left(S_{i} / N_{i}\right)$ at the output of the non-linear system which is known in electronic engineering as a perfect amplitude limiter. At the input the system is excited by a frequency modulated signal with power $\boldsymbol{S}_{i}$ and by the additive Gaussian white noise with power $N_{i}$, independent of the signal. It is assumed, moreover, that at the input and output of the limiter there are selective linear systems referred to as band-pass filters.

The output powers $S_{0}$ and $N_{0}$ will be determined in an indirect manner by determining, at the first stage of computation, the correlation function for output signals of the non-linear system. A new method will be applied for determining the correlation function, consisting in expanding the characteristic function of many arguments (involved in the expansion 
of the correlation function) into a functional series. The terms of the latter will be determined by moments of the input process before the non-linear system. The coefficients will be found in terms of definite integrals, the integrands being products of the distribution function of the process at the input and the derivatives of the function expressing the non-linearity of the system. The integrals are easy to find by any numerical method. That procedure was submitted first by Shutterly [7], and then developed by Schmelovsky and Kempe [6].

The classical analysis of the amplitude limiter, excited by an unmodulated signal and noise, was the object of the work of Davenport [1] in which the method of characteristic functions of many arguments and Fourier transformations were applied. The solution was found, here also, in the form of a series, the terms of which were expressed in terms of the gamma function $\Gamma(x)$ and hypergeometric functions which are very inconvenient for calculation by digital computers.

\section{ASSUMPTIONS}

Fig. 1 represents a diagram of the system to be analyzed.

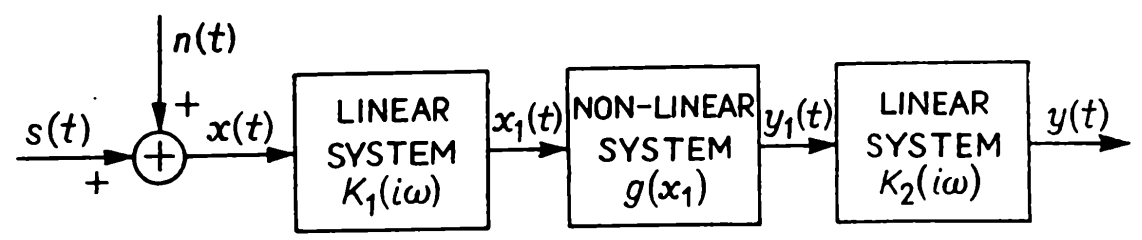

Fig. 1. Diagram of the system investigated

The characteristics of the system are

$$
K_{1}(i \omega)=K_{0} \exp \left[-\frac{\pi}{2}\left(\frac{\omega-\omega_{0}}{\Delta \omega}\right)^{2}\right], \quad-\infty<\omega<\infty
$$

where $K_{0}$ is the amplification for the frequency $\omega_{0} / 2 \pi$, and $\Delta \omega / 2 \pi$ the effective band-width of the filter.

The amplitude characteristic of the non-linear system is determined by the relation

$$
y_{1}(t)=g\left[x_{1}(t)\right]=\left\{\begin{aligned}
1 & \text { for } x(t)>0 \\
0 & \text { for } x(t)=0 \\
-1 & \text { for } x(t)<0
\end{aligned}\right.
$$


which is represented in Fig. 2, and

$$
K_{2}(i \omega)=\left\{\begin{array}{cc}
\frac{1}{2} \quad \text { for }-\omega_{0}-\frac{\Delta \omega}{2}<\omega<-\omega_{0}+\frac{\Delta \omega}{2} \\
\text { and } \omega_{0}-\frac{\Delta \omega}{2}<\omega<\omega_{0}+\frac{\Delta \omega}{2}, \\
0 \quad \text { for all other } \omega .
\end{array}\right.
$$

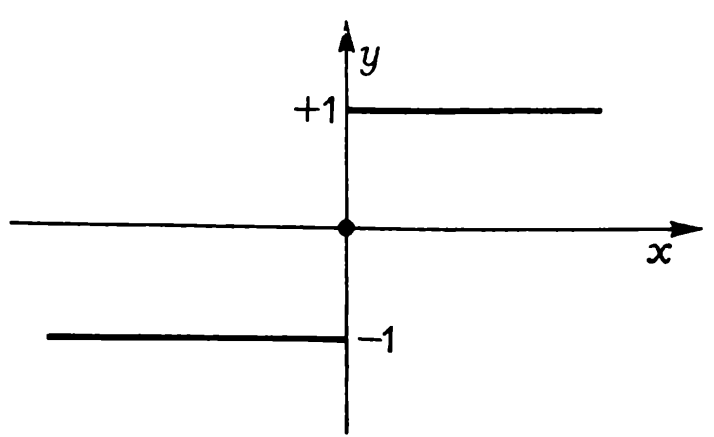

Fig. 2. Characteristic of the perfect amplitude limiter

The input of the system is acted on by a useful stationary [5] frequency modulated signal and by a perturbing stationary noise $n(t)$, statistically independent of the signal.

The signal $s(t)$ is expressed as

$$
s(t)=A \cos \left[\omega_{0} t+\varphi+\theta(t)\right]=A \sum_{r=-\infty}^{\infty} J_{r}(D) \cos \left(\omega_{0}+r \omega_{m}\right) t,
$$

where $A$ is the amplitude of the signal, $\omega_{0} / 2 \pi$ the carrier frequency of the signal, $\varphi$ the random initial phase angle of the signal with uniformly distributed probability density $w(\varphi)=1 / 2 \pi(0 \leqslant \varphi \leqslant 2 \pi)$, and $\theta(t)$ the phase angle of the signal, which depends on the modulating signal,

$$
\theta(t)=D \sin \left(\omega_{m} t+\psi\right),
$$

where $D$ is the modulation index, $\omega_{m} / 2 \pi$ the frequency of the modulating signal, and $\psi$ the random initial phase angle of the signal with uniformly distributed probability density $w(\psi)=1 / 2 \pi(0 \leqslant \psi \leqslant 2 \pi)$.

The statistical characteristics of the noise $n(t)$ are as follows:

It is a white stationary Gaussian noise with zero mean value and variance $\sigma^{2}$.

Its correlation function is $R_{n}(\tau)=N_{0} \delta(\tau) / 2$.

Its spectral power density is $G_{n}(\omega)=N_{0} / 2,-\infty<\omega<\infty$.

The total input signal is

$$
x(t)=s(t)+n(t) .
$$


Assuming the ratio $p=S_{i} / N_{i}$ of the power of the signal $S_{i}$ at the input to the non-linear system to the power of the noise $N_{i}$ to be an independent variable, our task is to find the power of the useful signal at the output $S_{0}(p)$, the output noise $N_{0}(p)$, the ratio $S_{0} / N_{0}=f(p)$ and the coefficient of improvement $\left(\mathbb{S}_{0} / N_{0}\right) /\left(S_{i} / N_{i}\right)=\varphi(p)$.

\section{SOLUTION OF THE PRoblem}

3.1. Determination of the parameters of the useful signal and the noise at the input of the non-linear system. The transfer characteristic of the linear filter at the input of the system is determined by (1). The effective band-width of the filter $\Delta \omega / 2 \pi$ is assumed large enough, so that signal (4) is passed by the filter with no distortion [8]:

$$
\begin{aligned}
G_{n^{\prime}}(\omega) & =G_{n}(\omega)\left|K_{1}(i \omega)\right|^{2} \\
& =\frac{N_{0} K_{0}^{2}}{2} \exp \left[-\pi\left(\frac{\omega-\omega_{0}}{\Delta \omega}\right)^{2}\right] .
\end{aligned}
$$

Making use of the Wiener-Khinchin theorem interrelating the spectral density function $G(\omega)$ and the correlation function $R(\omega)$ for a stationary process, we find $R_{n^{\prime}}(\tau)$ for the noise at the input to the non-linear system:

$$
\begin{aligned}
R_{n^{\prime}}(\tau) & =\frac{1}{\pi} \int_{0}^{\infty} G_{n^{\prime}}(\omega) \cos \omega \tau d \omega \\
& =\frac{1}{\pi} \int_{0}^{\infty} \frac{N_{0} K_{0}^{2}}{2} \exp \left[-\pi\left(\frac{\omega-\omega_{0}}{\Delta \omega}\right)^{2}\right] \cos \omega \tau d \omega .
\end{aligned}
$$
find

By changing variables according to the relation $\omega-\omega_{0}=m$, we

$$
R_{n^{\prime}}(\tau)=\frac{N_{0} K_{0}^{2}}{2} \int_{-\omega_{0}}^{\infty} \exp \left[-\pi\left(\frac{m}{\Delta \omega}\right)^{2}\right] \cos \left(\omega_{0}+m\right) \tau d m .
$$

If $\Delta \omega \ll \omega_{0}$, which is always the case for a real system, the lower integration limit $-\omega_{0}$ may be replaced by $-\infty$. We have then

$$
R_{n^{\prime}}(\tau)=\frac{N_{0} K_{0}^{2}}{2} \int_{-\infty}^{\infty} \exp \left[-\pi\left(\frac{m}{\Delta \omega}\right)^{2}\right] \cos \left(\omega_{0}+m\right) \tau d m .
$$


Integral (8) can be found in tables of integrals [3]. We have

$$
\begin{aligned}
R_{n^{\prime}}(\tau) & =\frac{N_{0} K_{0}^{2}}{2} \Delta \omega \exp \left[-\frac{1}{\pi}\left(\frac{\tau \Delta \omega}{2}\right)^{2}\right] \cos \omega_{0} \tau \\
& =\sigma_{1}^{2} \varrho(\tau) \cos \omega_{0} \tau,
\end{aligned}
$$

where the following notation has been introduced:

$$
\sigma_{1}^{2}=\frac{N_{0} K_{0}^{2}}{2} \Delta \omega \quad \text { and } \quad \varrho(\tau)=\exp \left[-\frac{1}{\pi}\left(\frac{\tau \Delta \omega}{2}\right)^{2}\right] .
$$

3.2. Derivation of the general expression describing the correlation function of the output signal of the non-linear system. Let the non-linear characteristic of the system be expressed, in a general manner, as $y(t)$ $=g[x(t)]$. We assume that there exist the Laplace transforms

$$
F(p)=\int_{-\infty}^{\infty} g(x) \exp (-p x) d x
$$

and

$$
y=g(x)=\frac{1}{2 \pi i} \int_{\sigma_{0}-i \infty}^{\sigma_{0}+i \infty} F(p) \exp (p x) d p,
$$

where $p=\sigma+i \lambda$ and $\sigma_{1}<\sigma<\sigma_{2}$.

In the general case, the correlation function for a stationary signal $y(t)$ is expressed as

$$
\begin{aligned}
R_{y}(\tau) & =\mathrm{E}\{y(t) y(t+\tau)\} \\
& =\mathrm{E}\{g[x(t)] g[x(t+\tau)]\}=\mathrm{E}\left\{g\left(x_{1}\right) g\left(x_{2}\right)\right\} \\
& =\mathrm{E}\left\{\frac{1}{(2 \pi i)^{2}} \int_{\sigma_{0}-i \infty}^{\sigma_{0}+i \infty} \int_{\sigma_{0}-i \infty}^{\sigma_{0}+i \infty} F\left(p_{1}\right) F\left(p_{2}\right) \exp \left(x_{1} p+x_{2} p\right) d p_{1} d p_{2}\right\} \\
& =\frac{1}{(2 \pi i)^{2}} \iint_{L} F\left(p_{1}\right) F\left(p_{2}\right) \varphi_{L}\left(-p_{1},-p_{2}\right) d p_{1} d p_{2},
\end{aligned}
$$

where

$$
\begin{aligned}
\varphi_{L}\left(-p_{1},-p_{2}\right) & =\mathrm{E}\left\{\exp \left(x_{1} p_{1}+x_{2} p_{2}\right)\right\} \\
& =\int_{-\infty}^{\infty} \int_{-\infty}^{\infty} w_{2}\left(x_{1}, x_{2}\right) \exp \left(+x_{1} p_{1}+x_{2} p_{2}\right) d x_{1} d x_{2}
\end{aligned}
$$

is the Laplace transform of the two-argument probability distribution of the random variables $x_{1}$ and $x_{2}$. 
Equation (11) can be given in another form:

$$
\varphi_{L}\left(p_{1}, p_{2}\right)=\varphi_{L_{1}}\left(p_{1}\right) \varphi_{L_{2}}\left(p_{2}\right) \varphi_{L_{12}}\left(p_{1}, p_{2}\right)
$$

Moreover, $\varphi_{L_{1,2}}\left(p_{1}, p_{2}\right)$ can be expanded in a series

$$
\varphi_{L_{1,2}}\left(p_{1}, p_{2}\right)=\left.\sum_{\mu=0}^{\infty} \sum_{\nu=0}^{\infty} \frac{p_{1}^{\mu}}{\mu !} \frac{p_{2}^{\nu}}{\nu !} \frac{\partial^{\mu+\nu}}{\partial p_{1}^{\mu} \partial p_{2}^{\nu}} \varphi_{L_{1,2}}\left(p_{1}, p_{2}\right)\right|_{p_{1}=p_{2}=0}
$$

Substituting (12) and (13) into (10), we find

$$
\begin{aligned}
& R_{y}(\tau)=\left.\sum_{\mu=0}^{\infty} \sum_{\nu=0}^{\infty} \frac{\partial^{\mu+\nu}}{\partial p_{1}^{\mu} \partial p_{2}^{\nu}} \varphi_{L_{1,2}}\left(-p_{1},-p_{2}\right)\right|_{p_{1}=p_{2}=0} \times \\
& \quad \times \frac{1}{2 \pi i} \int_{L} \frac{p_{1}^{\mu}}{\mu !} F\left(p_{1}\right) \varphi_{L_{1}}\left(-p_{1}\right) d p_{1} \cdot \frac{1}{2 \pi i} \int_{L} \frac{p_{2}^{\nu}}{\nu !} F\left(p_{2}\right) \varphi_{L_{2}}\left(-p_{2}\right) d p_{2} .
\end{aligned}
$$

It is known that

$$
\begin{aligned}
\left.(-1)^{\mu+\nu} \frac{\partial^{\mu+\nu}}{\partial p_{1}^{\mu} \partial p_{2}^{\nu}} \varphi_{L}\left(-p_{1},-p_{2}\right)\right|_{p_{1}=p_{2}=0}=\mathrm{E}\left\{x_{1} x_{2}\right\} \\
=(-1)^{\mu+\nu} \sum_{r=0}^{\mu} \sum_{s=0}^{\nu}\left(\begin{array}{l}
\mu \\
r
\end{array}\right)\left(\begin{array}{l}
\nu \\
s
\end{array}\right) \frac{\partial^{r}}{\partial p_{1}^{r}} \varphi_{L_{1}}\left(-p_{1}\right) \frac{\partial^{s}}{\partial p_{2}^{s}} \times \\
\\
\times\left.\varphi_{L_{2}}\left(-p_{2}\right) \frac{\partial^{\mu-r+\nu-s}}{\partial p_{1}^{\mu-r} \partial p_{2}^{\nu-8}} \varphi_{L_{1,2}}\left(-p_{1},-p_{2}\right)\right|_{p_{1}=p_{2}=0} \\
=\sum_{r=0}^{\mu} \sum_{s=0}^{\nu}\left(\begin{array}{l}
\mu \\
r
\end{array}\right)\left(\begin{array}{l}
\nu \\
s
\end{array}\right) \mathrm{E}\left\{x_{1}^{r}\right\} \mathrm{E}\left\{x_{2}^{s}\right\} \mathrm{E}\left\{x_{1 a c}^{\mu-r} x_{2 a c}^{\nu-s}\right\}
\end{aligned}
$$

or

$$
\mathrm{E}\left\{x_{1}^{\mu} x_{2}^{\nu}\right\}=\mathrm{E}\left\{\sum_{r=0}^{\mu}\left(\begin{array}{l}
\mu \\
r
\end{array}\right) \mathrm{E}\left\{x_{1}^{r}\right\} x_{1 a c}^{\mu-r} \cdot \sum_{s=0}^{\nu}\left(\begin{array}{l}
\nu \\
s
\end{array}\right) \mathrm{E}\left\{x_{2}^{s}\right\} x_{2 a c}^{\nu-s}\right\}
$$

By virtue of (15), we find a recurrence equation for computing $x_{1 a c}^{\mu-r}$ and $x_{2 a c}^{\nu-s}$ which we call, after Shutterly [7], ac quantities:

$$
x_{1}^{\mu}=\sum_{r=0}^{\mu}\left(\begin{array}{c}
\mu \\
r
\end{array}\right) \mathrm{E}\left\{x_{1}^{r}\right\} x_{1 a c}^{\mu-r} \quad \text { and } \quad x_{2}^{\nu}=\sum_{s=0}^{\nu}\left(\begin{array}{l}
\nu \\
s
\end{array}\right) \mathrm{E}\left\{x_{2}^{s}\right\} x_{2 a c}^{\nu-s} .
$$
follows:

The first values of the quantity $x_{a c}$ are expressed in terms of $x$ as 
$x_{a c}^{0}=1$ for $\mu=0$ (it being assumed additionally that $\mathrm{E}\{x\}=0$ ),

$x_{a c}^{1}=x \quad$ for $\mu=1$,

$x_{a c}^{2}=x^{2}-\mathrm{E}\left\{x^{2}\right\} \quad$ for $\mu=2$,

$x_{a c}^{3}=x^{3}-3 \mathrm{E}\left\{x^{2}\right\} x-\mathrm{E}\left\{x^{3}\right\} \quad$ for $\mu=3$,

Making use of the ac quantities just introduced, the correlation function (14) can now be rewritten as

$$
\begin{aligned}
R_{y}(\tau)=\mathrm{E}\left\{\sum_{\mu=0}^{\infty} \frac{x_{1 a c}^{\mu}}{2 \pi i \mu !} \int_{L} p_{1}^{\mu} F\left(p_{1}\right) \varphi_{L_{1}}\left(-p_{1}\right) d p_{1} \times\right. \\
\left.\times \sum_{\nu=0}^{\infty} \frac{x_{2 a c}^{\nu}}{2 \pi i v !} \int_{L} p_{2}^{\nu} F\left(p_{2}\right) \varphi_{L_{2}}\left(-p_{2}\right) d p_{2}\right\} .
\end{aligned}
$$

We shall now be concerned with the determination of the integral

$$
\frac{1}{2 \pi i} \int_{L} p_{1}^{\mu} F\left(p_{1}\right) \varphi_{L_{1}}\left(-p_{1}\right) d p_{1}
$$

involved in (17). To this end, let us introduce a new auxiliary function

$$
r(x)=\int_{-\infty}^{\infty} g(u) w[-(x-u)] d u,
$$

where $w(x)$ is the probability distribution of the variable $x$, and $g(x)$ is a function determining the non-linearity of the system analyzed. form

It will also be assumed that there exists, for $r(x)$, the Laplace trans-

$$
\begin{aligned}
R(p)=\int_{-\infty}^{\infty} r(x) \exp [-p x] d x & =\int_{-\infty}^{\infty}\left\{\int_{-\infty}^{\infty} g(u) w[-(x-u)] d u\right\} \exp (-p x) d x \\
& =\int_{-\infty}^{\infty} g(u)\left\{\int_{-\infty}^{\infty} w[-(x-u)] \exp (-p x) d x\right\} d u
\end{aligned}
$$

Substituting $v=-x+u$, we have

$$
R(p)=\int_{-\infty}^{\infty} g(u) e^{-p u} d u \int_{-\infty}^{\infty} w(v) e^{p v} d v=F(p) \varphi_{L}(-p) .
$$

Making use of the inverse Laplace transform for the derivative $r^{(n)}(x)$, we obtain

$$
\left.r^{(n)}(x)\right|_{x=0}=\left.\frac{1}{2 \pi i} \int_{L} p^{n} R(p) d p\right|_{x=0}=\frac{1}{2 \pi i} \int_{L} p^{n} F(p) \varphi_{L}(-p) d p .
$$


With the aid of (20) each factor in the equation (17) can be expressed in the form

$$
\begin{aligned}
& \sum_{\mu=0}^{\infty} \frac{x_{1 a c}^{\mu}}{2 \pi i \mu !} \int_{L} p_{1}^{\mu} F\left(p_{1}\right) \varphi_{L}\left(-p_{1}\right) d p_{1}=\left.\sum_{\mu=0}^{\infty} \frac{x_{1 a c}^{\mu}}{\mu !} \frac{d^{\mu}}{d x^{\mu}} r(x)\right|_{x=0} \\
= & \sum_{\mu=0}^{\infty} \frac{x_{1 a c}^{\mu}}{\mu !} \frac{d^{\mu}}{d x^{\mu}} \int_{-\infty}^{\infty} g(u) w[-(x-u)] d u=\sum_{\mu=0}^{\infty} \frac{x_{1 a c}^{\mu}}{\mu !} \int_{-\infty}^{\infty} g_{l}^{(\mu)}(u) w(u) d u .
\end{aligned}
$$

The following notation has been introduced in the latter integral: $g_{l}^{(\mu)}(x)=g^{(\mu)}(x)$ for those values of $x$ for which $g^{(\mu)}(x)$ exists;

$g_{l}^{(\mu)}(x)=g^{(\mu)}(x)=\delta^{(\mu-\gamma-1)}\left(x-x_{n}\right)\left\{g^{(\gamma)}\left(x_{n}+\varepsilon\right)-g^{(\gamma)}\left(x_{n}-\varepsilon\right)\right\}$ for those $x_{n}$ for which the $\gamma$ derivative still exists;

$\delta^{(n)}(x)=0$ for $x \neq 0$;

$$
\int_{-\infty}^{\infty} \delta^{(n)}\left(x-x_{0}\right) f(x) d x=\left.(-1)^{n} f^{(n)}(x)\right|_{x=x_{0}} .
$$

By (21) the correlation function $R_{y}(\tau)$ can be expressed in the final form

$$
\begin{aligned}
& R_{y}(\tau) \\
& =\sum_{\mu=0}^{\infty} \sum_{\nu=0}^{\infty} \frac{1}{\mu ! \nu !} \int_{-\infty}^{\infty} g_{l}^{(\mu)}(u) w(u) d u \int_{-\infty}^{\infty} g_{l}^{(\nu)}(u) w(u) d u \mathrm{E}\left\{x_{1 a c}^{\mu} x_{2 a c}^{\nu}\right\}
\end{aligned}
$$

If the input signal of the non-linear system considered is a sum of statistically independent signals (a sum of the useful signal and the noise), $x(t)=x_{1}(t)+x_{2}(t)$, then

$$
\varphi_{L x_{1}+x_{2}}\left(p_{1}, p_{2}\right)=\varphi_{L x_{1}}\left(p_{1}, p_{2}\right) \varphi_{L x_{2}}\left(p_{1}, p_{2}\right)
$$

and the correlation function is expressed, by virtue of (10), by the equation

$$
\begin{aligned}
& R_{y}(\tau) \\
= & \frac{1}{(2 \pi i)^{2}} \iint_{L} F\left(p_{1}\right) F\left(p_{2}\right) \varphi_{L x_{1}}\left(-p_{1},-p_{2}\right) \varphi_{L x_{2}}\left(-p_{1},-p_{2}\right) d p_{1} d p_{2} .
\end{aligned}
$$

Expressions (22) and (23) are fundamental and will be used in what follows to solve the problem stated.

The determination of $R_{y}(\tau)$ for the output signal of the non-linear system consists in finding the quantities $x_{a c}$, the mean values $\mathbf{E}\left\{x_{1 a c}^{\mu} x_{2 a c}^{\nu}\right\}$, 
the integrals and sums involved in (22) from the prescribed probability densities $w(x)$ for the input signals and the characteristic $g(x)$ of the non-linear system.

3.3. Determination of $R_{y_{1}}(\tau)$ for the output signal of the non-linear system. At the input to the amplitude limiter statistically independent signals $s(t)$ and $n^{\prime}(t)$ are superimposed. The correlation function for the signals $y_{1}(t)$ at the output of the limiter is determined by (23) as follows:

$$
R_{y_{1}}(\tau)=\frac{1}{(2 \pi i)^{2}} \iint_{L} F\left(p_{1}\right) F\left(p_{2}\right) \varphi_{L s}\left(-p_{1},-p_{2}\right) \varphi_{L n^{\prime}}\left(-p_{1},-p_{2}\right) d p_{1} d p_{2}
$$

The transform $\varphi_{L s}\left(-p_{1},-p_{2}\right)$ is expressed by the relation

where

$$
\begin{aligned}
\varphi_{L s}\left(-p_{1},-p_{2}\right) & =\int_{-\infty}^{\infty} \int_{-\infty}^{\infty} w\left(s_{1}, s_{2}\right) \exp \left(p_{1} s_{1}+p_{2} s_{2}\right) d s_{1} d s_{2} \\
& =\mathrm{E}\left\{\exp \left(p_{1} s_{1}+p_{2} s_{2}\right)\right\}
\end{aligned}
$$

$$
\begin{aligned}
& s_{1}=s(t)=A \cos \left[\omega_{0} t+\theta(t)+\varphi\right]=A \cos \alpha, \\
& s_{2}=s(t+\tau)=A \cos \left[\omega_{0}(t+\tau)+\theta(t+\tau)+\varphi\right]=A \cos \beta .
\end{aligned}
$$

According to the Jacobi-Enger formula (see [2]), we have

$$
\begin{aligned}
& \exp \left(p_{1} A \cos \alpha\right)=\sum_{a=0}^{\infty} \varepsilon_{a} I_{a}\left(p_{1} A\right) \cos a \alpha, \\
& \exp \left(p_{2} A \cos \beta\right)=\sum_{b=0}^{\infty} \varepsilon_{b} I_{b}\left(p_{2} A\right) \cos b \beta,
\end{aligned}
$$

where $I(p, A)$ is the modified Bessel function of the argument $p A$, and

$$
\varepsilon_{a, b}= \begin{cases}1 & \text { for } a, b=0 \\ 2 & \text {, for } a, b=1,2, \ldots,\end{cases}
$$

are Neumann coefficients.

Equation (24) can now be rewritten as

$$
\begin{aligned}
\varphi_{L s}\left(-p_{1},-p_{2}\right) & =\mathrm{E}\left\{\sum_{a=0}^{\infty} \varepsilon_{a} I_{a}\left(p_{1} A\right) \cos a \alpha \sum_{b=0}^{\infty} \varepsilon_{b} I_{b}\left(p_{2} A\right) \cos b \beta\right\} \\
& =\sum_{a=0}^{\infty} \sum_{b=0}^{\infty} I_{a}\left(p_{1} A\right) I_{b}\left(p_{2} A\right) \mathrm{E}\left\{\varepsilon_{a} \cos \alpha \cdot \varepsilon_{b} \cos b \beta\right\}
\end{aligned}
$$


Since

$$
\begin{aligned}
\cos a a & =\cos a\left[\omega_{0} t+D \sin \left(\omega_{m} t+\psi\right)+\varphi\right] \\
& =\operatorname{Re}\left\{\exp \left[i a\left(\omega_{0} t+\varphi\right)\right] \sum_{r=-\infty}^{\infty} J_{r}(a D)\left[\cos \left(\omega_{m} t+\psi\right) r+i \sin \left(\omega_{m} t+\psi\right)\right]\right\} \\
& =\operatorname{Re} \sum_{r=-\infty}^{\infty} J_{r}(a D) \exp \left\{i\left[a\left(\omega_{0} t+\varphi\right)+r\left(\omega_{m} t+\psi\right)\right]\right\} \\
& =\sum_{r=-\infty}^{\infty} J_{r}(a D) \cos \left[a\left(\omega_{0} t+\varphi\right)+r\left(\omega_{m} t+\psi\right)\right],
\end{aligned}
$$

where $J_{r}(a D)$ is the Bessel function of the $r$-th order, we have

$$
\begin{aligned}
\mathrm{E}\left\{\varepsilon_{a} \cos a \alpha \cdot \varepsilon_{b} \cos b \beta\right\} & =\frac{1}{2} \varepsilon_{a} \varepsilon_{b} \mathrm{E}\{\cos (a \alpha+b \beta)+\cos (a \alpha-b \beta)\} \\
& = \begin{cases}\varepsilon_{a}^{2} \mathrm{E}\{\cos a \alpha \cos a \beta\} & \text { for } a=b, \\
0 & \text { for } a \neq b .\end{cases}
\end{aligned}
$$

Then expression (25) becomes

$$
\begin{aligned}
& \varphi_{L s}\left(-p_{1},-p_{2}\right)=\varepsilon_{a}^{2} \sum_{r=-\infty}^{\infty} \sum_{s=-\infty}^{\infty} J_{r}(a D) J_{s}(a D) \times \\
& \times \mathrm{E}\left\{\cos \left[a\left(\omega_{0} t+\varphi\right)+r\left(\omega_{m} t+\psi\right)\right] \cos \left[a\left(\omega_{0}(t+\tau)+\varphi\right)+s\left(\omega_{m}(t+\tau)+\psi\right)\right]\right\} \\
& =\left\{\begin{array}{cc}
\varepsilon_{a}^{2} \sum_{r=-\infty}^{\infty} J_{r}^{2}(a D) \mathrm{E}\left\{\cos \left[a\left(\omega_{0} t+\varphi\right)+r\left(\omega_{m} t+\psi\right)\right] \times\right. \\
\left.\times \cos \left[a\left(\omega_{0}(t+\tau)+\varphi\right)+r\left(\omega_{m}(t+\tau)+\psi\right)\right]\right\} & \text { for } s=r, \\
0 & \text { for } s \neq r,
\end{array}\right.
\end{aligned}
$$

(26) $\varepsilon_{a}^{2} \sum_{r=-\infty}^{\infty} J_{r}^{2}(a D) \mathrm{E}\left\{\cos \left[a\left(\omega_{0} t+\varphi\right)+r\left(\omega_{m} t+\psi\right)\right] \times\right.$

$$
\begin{aligned}
& \left.\times \cos \left[a\left(\omega_{0}(t+\tau)+\varphi\right)+r\left(\omega_{m}(t+\tau)+\psi\right)\right]\right\} \\
= & \varepsilon_{a}^{2} \sum_{r=-\infty}^{\infty} J_{r}^{2}(a D) \frac{1}{2} \frac{1}{2 \pi} \int_{-\pi}^{\pi}\left[\frac{1}{2 \pi} \int_{-\pi}^{\pi} \cos \left(a \omega_{0}+r \omega_{m}\right) \tau d \varphi\right] d \psi \\
= & \sum_{r=-\infty}^{\infty} \varepsilon_{a} J_{r}^{2}(a D) \cos \left(a \omega_{0}+r \omega_{m}\right) \tau .
\end{aligned}
$$

Expression (26) has been obtained for the distributions of the probability densities assumed for the angles $\varphi$ and $\psi$. Substituting (26) into (25), we have

$$
\varphi_{L s}\left(-p_{1},-p_{2}\right)=\sum_{a=0}^{\infty} \sum_{r=-\infty}^{\infty} \varepsilon_{a} I_{a}\left(p_{1} A\right) I_{a}\left(p_{2} A\right) J_{r}^{2}(a D) \cos \left(a \omega_{0}+r \omega_{m}\right) \tau
$$


Making use of (27), we write the correlation function $R_{\nu_{1}}(\tau)$ in the form

$$
\begin{aligned}
R_{v_{1}}(\tau) & =\frac{1}{(2 \pi i)^{2}} \sum_{a=0}^{\infty} \sum_{r=-\infty}^{\infty} \varepsilon_{a} J_{r}^{2}(a D) \cos \left(a \omega_{0}+r \omega_{m}\right) \tau \times \\
& \times \iint_{L} F\left(p_{1}\right) F\left(p_{2}\right) I_{a}\left(p_{1} A\right) I_{a}\left(p_{2} A\right) \varphi_{L n^{\prime}}\left(-p_{1},-p_{2}\right) d p_{1} d p_{2}
\end{aligned}
$$

The integral of (28) can be transformed in the following manner. It is known (see [3]) that

$$
\begin{gathered}
J_{n}(z)=\frac{(-i)^{n}}{2 \pi} \int_{-\pi}^{\pi} \exp (i z \cos \psi) \cos n \psi d \psi \\
I_{n}(z)=(-i)^{n} J_{n}(i z) \quad \text { and } \quad J_{n}(-z)=(-1)^{n} J_{n}(z),
\end{gathered}
$$

therefore,

$$
I_{n}(z)=\frac{1}{2 \pi} \int_{-\pi}^{\pi} \exp [z \cos \psi] \cos n \psi d \psi
$$

Now

(29) $F\left(p_{1}\right) I_{n}\left(p_{1} A\right)=\frac{1}{2 \pi} \int_{-\infty}^{\infty} g\left(x_{1}\right) e^{-p_{1} x_{1}} d x_{1} \int_{-\pi}^{\pi} \exp \left(p_{1} A \cos \alpha\right) \cos a \alpha d \alpha$

$$
=\frac{1}{2 \pi} \int_{-\infty}^{\infty} \int_{-\pi}^{\pi} g\left(x_{1}\right) \exp \left[-p_{1}\left(x_{1}-A \cos \alpha\right)\right] \cos \alpha \alpha d \alpha d x_{1} .
$$

Since in the considered case we have

$$
x_{1}(t)=s(t)+n^{\prime}(t)=A \cos \alpha+n^{\prime},
$$

expression (29) can be rewritten in the form

$$
\begin{aligned}
F\left(p_{1}\right) I_{n}\left(p_{1} A\right) & =\frac{1}{2 \pi} \int_{-\infty}^{\infty} \int_{-\pi}^{\pi} g\left(A \cos \alpha+n^{\prime}\right) e^{-p n^{\prime}} \cos a \alpha d \alpha d n^{\prime} \\
& =\int_{-\infty}^{\infty}\left[\frac{1}{2 \pi} \int_{-\pi}^{\pi} g\left(A \cos \alpha+n^{\prime}\right) \cos a \alpha d \alpha\right] e^{-p n^{\prime}} d n^{\prime} \\
& =\int_{-\infty}^{\infty} g_{a}\left(n^{\prime}\right) e^{-p n^{\prime}} d n^{\prime}=F_{a}\left(p_{1}\right)=\mathscr{L}\left\{g_{a}\left(n^{\prime}\right)\right\}
\end{aligned}
$$


Expression (30) can be treated as a Laplace transform of the function

$$
g_{a}\left(n^{\prime}\right)=\frac{1}{2 \pi} \int_{-\pi}^{\pi} g\left(A \cos \alpha+n^{\prime}\right) \cos a \alpha \dot{d} \alpha
$$

Substituting (30) into (28), we have

$$
\begin{aligned}
R_{y_{1}}(\tau)=\frac{1}{(2 \pi i)^{2}} \sum_{a=0}^{\infty} & \sum_{r=-\infty}^{\infty} \varepsilon_{a} J_{r}^{2}(a D) \cos \left(a \omega_{0}+r \omega_{m}\right) \tau \times \\
& \times \iint_{L} F_{a}\left(p_{1}\right) F_{a}\left(p_{2}\right) \varphi_{L n^{\prime}}\left(-p_{1},-p_{2}\right) d p_{1} d p_{2}
\end{aligned}
$$

The integral in (31) has exactly the same form as expression (10), therefore, making use of another form of (10), namely (22), we can replace expression (31) by

$$
\begin{aligned}
& R_{\nu_{1}}(\tau)=\sum_{a=0}^{\infty} \sum_{r=-\infty}^{\infty} \varepsilon_{a} J_{r}^{2}(a D) \cos \left(a \omega_{0}+r \omega_{m}\right) \tau \times \\
& \times \sum_{\mu=0}^{\infty} \sum_{\nu=0}^{\infty} \frac{1}{\mu ! \nu !} \int_{-\infty}^{\infty} g_{a}^{(\mu)}\left(n^{\prime}\right) w\left(n^{\prime}\right) d n^{\prime} \int_{-\infty}^{\infty} g_{a}^{(\nu)}\left(n^{\prime}\right) w\left(n^{\prime}\right) d n^{\prime} \mathrm{E}\left\{n_{1 a c}^{\mu} n_{2 a c}^{\nu}\right\}
\end{aligned}
$$

where

$$
g_{a}^{(\mu)}\left(n^{\prime}\right)=\frac{\partial^{\mu}}{\partial n^{\prime \mu}}\left\{\frac{1}{2 \pi} \int_{-\pi}^{\pi} g\left(n^{\prime}+A \cos \alpha\right) \cos a \alpha d \alpha\right\} .
$$

Writing

$$
\int_{-\infty}^{\infty} g_{a}^{(\mu)}\left(n^{\prime}\right) w\left(n^{\prime}\right) d n^{\prime} \int_{-\infty}^{\infty} g_{a}^{(\nu)}\left(n^{\prime}\right) w\left(n^{\prime}\right) d n^{\prime}=h_{a \mu \nu}
$$

we can expressed the correlation function $R_{\nu_{1}}(\tau)$ in the most general form

$$
R_{v_{1}}(\tau)=\sum_{a=0}^{\infty} \sum_{r=-\infty}^{\infty} \sum_{\mu=0}^{\infty} \sum_{\nu=0}^{\infty} \varepsilon_{a} J_{r}^{2}(a D) \cos \left(a \omega_{0}+r \omega_{m}\right) \tau \frac{h_{a \mu \nu}}{\mu ! \nu !} \mathbf{E}\left\{n_{1 a c}^{\prime \mu} n_{2 a c}^{\prime \nu}\right\}
$$

The correlation function (33) can be expressed in the form of a sum of three components, the first one corresponding to the useful output signal of the non-linear system and its harmonics, the second one to the 
noise at the output, and the third one to the noise resulting from the combination of the signal and the noise due to the non-linearity.

Introducing the notation

$$
\begin{gathered}
R_{s a}(\tau)=\sum_{r=-\infty}^{\infty} J_{r}^{2}(a D) \cos \left(a \omega_{0}+r \omega_{m}\right) \tau \\
R_{n^{\prime} \mu \nu}(\tau)=\mathrm{E}\left\{n_{1 a c}^{\prime \mu} n_{2 a c}^{\prime \nu}\right\}
\end{gathered}
$$

and bearing in mind that $R_{n^{\prime} 00}(\tau)=1$ for $\mu=\nu=0$, expression (33) can be written as

$$
\begin{aligned}
R_{v_{1}}(\tau)=\sum_{a=0}^{\infty} \varepsilon_{a} R_{s a}(\tau) h_{a 00} & +\sum_{\mu=1}^{\infty} \sum_{\nu=1}^{\infty} R_{n^{\prime} \mu \nu}(\tau) \frac{h_{0 \mu \nu}}{\mu ! \nu !}+ \\
& +\sum_{a=1}^{\infty} \sum_{\mu=1}^{\infty} \sum_{\nu=1}^{\infty} \varepsilon_{a} R_{s a}(\tau) R_{n^{\prime} \mu \nu}(\tau) \frac{h_{a \mu \nu}}{\mu ! \nu !} .
\end{aligned}
$$

By applying the Wiener-Khinchin theorem to (34), we can determine the output frequency spectrum of the signal $y_{1}(t)$ of the amplitude limiter. It will be composed of the spectrum of the useful signal and of the noise. The spectrum of the useful signal should be identical (the lines of the spectrum may differ by a constant factor) with the spectrum of the useful signal $s(t)$ at the input to the amplitude limiter. The remaining components of the spectrum should be classified as the noise.

3.4. Determination of $R_{y}(\tau)$ for the output signal of the system. According to the scheme in Fig. 1 at the output of the amplitude limiter, there is a band-pass filter with a transfer function as determined by (3), therefore, the correlation function for the output signal $y(t)$ of the system is determined as follows:

$$
\begin{aligned}
R_{y}(\tau)=2 R_{s 1}(\tau) h_{100}+\sum_{\mu=1}^{\infty} \sum_{\nu=1}^{\infty} R_{n^{\prime} \mu \nu}(\tau) \frac{h_{0 \mu \nu}}{\mu ! \nu !}+ \\
+2 \sum_{a=1}^{\infty} \sum_{\mu=1}^{\infty} \sum_{\nu=1}^{\infty} R_{s a}(\tau) R_{n^{\prime} \mu \nu}(\tau) \frac{h_{a \mu \nu}}{\mu ! \nu !} .
\end{aligned}
$$

This is a general expression for $R_{y}(\tau)$. In subsequent numerical computations we shall confine ourselves to the summation indices $n=1,2$ and $\mu, \nu=1,2$. This is in agreement with the principles of correlation analysis, namely, those of confining the computation to the moments of the second order. Moreover, it follows from the subsequent analysis that the terms of the series decrease rapidly with increasing index which justifies also the simplification assumed. 
Making use of relation (16) we shall find $R_{n^{\prime} \mu \nu}(\tau)=\mathrm{E}\left\{n_{1 a c}^{\prime \mu} n_{2 a c}^{\prime \nu}\right\}$. By the assumptions and the argument of Section 3.1, we have:

$$
\begin{gathered}
\mathrm{E}\left\{n^{\prime}(t)\right\}=0, \\
\mathrm{E}\left\{\left[n^{\prime}(t)\right]^{2}\right\}=\frac{N_{0} K_{0}^{2}}{2} \Delta \omega=\sigma_{1}^{2}, \\
R_{n^{\prime}}(\tau)=\mathrm{E}\left\{n^{\prime}(t) n^{\prime}(t+\tau)\right\}=\sigma_{1}^{2} \varrho(\tau) \cos \omega_{0} \tau \\
=\frac{N_{0} K_{0}^{2}}{2} \Delta \omega \exp \left[-\frac{1}{\pi}\left(\frac{\tau \Delta \omega}{2}\right)^{2}\right] \cos \omega_{0} \tau,
\end{gathered}
$$

$$
\begin{aligned}
R_{n^{\prime} 11}(\tau) & =\mathrm{E}\left\{n_{1 a c}^{\prime} n_{2 a c}^{\prime}\right\}=\mathrm{E}\left\{n^{\prime}(t) n^{\prime}(t+\tau)\right\}=\sigma_{1}^{2} \varrho(\tau) \cos \omega_{0} \tau, \\
R_{n^{\prime} 12}(\tau) & =\mathrm{E}\left\{n_{1 a c}^{\prime} n_{2 a c}^{\prime 2}\right\}=\mathrm{E}\left\{n^{\prime}(t)\left[n^{\prime 2}(t+\tau)-\mathrm{E}\left(n^{\prime 2}(t+\tau)\right)\right]\right\} \\
& =\mathrm{E}\left\{n^{\prime}(t) n^{\prime 2}(t+\tau)-n^{\prime}(t) \mathrm{E}\left(n^{\prime 2}(t+\tau)\right)\right\} \\
& =\mathrm{E}\left\{n^{\prime}(t) n^{\prime 2}(t+\tau)\right\}-\mathrm{E}\left\{n^{\prime}(t) \mathrm{E}\left(n^{\prime 2}(t+\tau)\right)\right\}=0, \\
& \mathrm{E}\left\{n^{\prime}(t) n^{\prime 2}(t+\tau)\right\}=0
\end{aligned}
$$

(being an odd moment of the Gaussian distribution),

$$
R_{n^{\prime} 21}(\tau)=0,
$$

$$
\begin{gathered}
R_{n^{\prime} 22}(\tau)=\mathrm{E}\left\{\left[n^{\prime 2}(t)-\mathrm{E}\left(n^{\prime 2}(t)\right)\right]\left[n^{\prime 2}(t+\tau)-\mathrm{E}\left(n^{\prime 2}(t+\tau)\right)\right]\right\} \\
=\mathrm{E}\left\{n^{\prime 2}(t) n^{\prime 2}(t+\tau)\right\}-\mathrm{E}\left\{n^{\prime 2}(t)\right\} \mathrm{E}\left\{n^{\prime 2}(t+\tau)\right\} \\
=\sigma_{1}^{4}\left[1+2 \varrho^{2}(\tau) \cos ^{2} \omega_{0} \tau\right]-\sigma_{1}^{4}=\sigma_{1}^{4} \varrho^{2}(\tau)\left[1+\cos 2 \omega_{0} \tau\right] \\
R_{s 1}(\tau)=\sum_{r=-\infty}^{\infty} J_{r}^{2}(D) \cos \left(\omega_{0}+r \omega_{m}\right) \tau \\
R_{82}(\tau)=\sum_{r=-\infty}^{\infty} J_{r}^{2}(2 D) \cos \left(2 \omega_{0}+r \omega_{m}\right) \tau
\end{gathered}
$$

We now determine the coefficients $h_{a \mu \nu}$. We have

$$
\begin{aligned}
h_{100} & =\left\{\int_{-\infty}^{\infty} g_{1}^{(0)}\left(n^{\prime}\right) w\left(n^{\prime}\right) d n^{\prime}\right\}^{2} \\
& =\left\{\int_{-\infty}^{\infty} \frac{1}{2 \pi}\left[\int_{-\pi}^{\pi} g^{(0)}\left(n^{\prime}+A \cos \alpha\right) \cos \alpha d \alpha\right] w\left(n^{\prime}\right) d n^{\prime}\right\}^{2} \\
& =\left\{\frac{1}{2 \pi} \int_{-\pi}^{\pi}\left[\int_{-\infty}^{\infty} g\left(n^{\prime}+A \cos \alpha\right) w\left(n^{\prime}\right) d n^{\prime}\right] \cos \alpha d \alpha\right\}^{2} .
\end{aligned}
$$


In agreement with (2),

$$
\begin{aligned}
g\left(n^{\prime}+A \cos \alpha\right) & =\left\{\begin{aligned}
1 & \text { for } n^{\prime}+A \cos \alpha>0 \\
0 & \text { for } n^{\prime}+A \cos \alpha=0 \\
-1 & \text { for } n^{\prime}+A \cos \alpha<0
\end{aligned}\right. \\
\int_{-\infty}^{\infty} g\left(n^{\prime}+A \cos \alpha\right) w\left(n^{\prime}\right) d n^{\prime} & =-\int_{-\infty}^{-A \cos \alpha} w\left(n^{\prime}\right) d n^{\prime}+\int_{-A \cos \alpha}^{\infty} w\left(n^{\prime}\right) d n^{\prime} \\
& =-\frac{1}{2}+\int_{-A \cos \alpha}^{0} w\left(n^{\prime}\right) d n^{\prime}+\int_{-A \cos \alpha}^{\infty} w\left(n^{\prime}\right) d n^{\prime} \\
& =-2 \int_{0}^{-A \cos \alpha} w\left(n^{\prime}\right) d n^{\prime} .
\end{aligned}
$$

Because

$$
\begin{gathered}
w\left(n^{\prime}\right)=\frac{1}{\sqrt{2 \pi} \sigma_{1}} \exp \left[-\frac{n^{\prime 2}}{2 \sigma_{1}^{2}}\right], \\
h_{100}=\left\{\frac{1}{2 \pi} \int_{-\pi}^{\pi}\left[-2 \int_{0}^{-\Delta \cos \alpha} w\left(n^{\prime}\right) d n^{\prime}\right] \cos \alpha d a\right\}^{2} .
\end{gathered}
$$

Substituting

$$
\begin{gathered}
u^{(1)}=\cos \alpha, \quad u=\sin \alpha \\
v=\int_{0}^{-A \cos \alpha} w\left(n^{\prime}\right) d n^{\prime}, \quad v^{(1)}=w(-A \cos \alpha) A \sin \alpha
\end{gathered}
$$

and integrating by parts,

$$
h_{100}=\left\{-\left.\frac{1}{\pi} \sin \alpha \int_{0}^{-A \cos \alpha} w\left(n^{\prime}\right) d n^{\prime}\right|_{-\pi} ^{\pi}+\frac{A}{\pi} \int_{-\pi}^{\pi} \sin ^{2} \alpha w(-A \cos \alpha) d \alpha\right\}^{2},
$$

we obtain

$$
\begin{aligned}
h_{100} & =\frac{A^{2}}{\pi^{2}}\left\{\int_{-\pi}^{\pi} \sin ^{2} \alpha w(-A \cos \alpha) d \alpha\right\}^{2} \\
& =\frac{A^{2}}{\pi^{2} \sigma_{1}^{2}}\left\{\frac{1}{\sqrt{2 \pi}} \int_{-\pi}^{\pi} \sin ^{2} \alpha \exp \left[-\frac{A^{2}}{2 \sigma_{1}^{2}} \cos ^{2} \alpha\right] d \alpha\right\}^{2}
\end{aligned}
$$




$$
\begin{aligned}
h_{011} & =\left\{\int_{-\infty}^{\infty} g_{0}^{(1)}\left(n^{\prime}\right) w\left(n^{\prime}\right) d n^{\prime}\right\}^{2} \\
& =\left\{\int_{\infty}^{\infty} \frac{1}{2 \pi}\left[\int_{-\pi}^{\pi} g^{(1)}\left(n^{\prime}+A \cos \alpha\right) d \alpha\right] w\left(n^{\prime}\right) d n^{\prime}\right\}^{2} \\
& =\left\{\frac{1}{2 \pi} \int_{-\pi}^{\pi}\left[\int_{-\infty}^{\infty} g^{(1)}\left(n^{\prime}+A \cos \alpha\right) w\left(n^{\prime}\right) d n^{\prime}\right] d \alpha\right\}^{2}
\end{aligned}
$$

Since

$$
g^{(1)}\left(n^{\prime}+A \cos \alpha\right)=2 \delta\left(n^{\prime}+A \cos \alpha\right)
$$

$$
\begin{aligned}
\int_{-\infty}^{\infty} g^{(1)}\left(n^{\prime}+A \cos \alpha\right) & w\left(n^{\prime}\right) d n^{\prime} \\
=2 & \int_{-\infty}^{\infty} \delta\left(n^{\prime}+A \cos \alpha\right) w\left(n^{\prime}\right) d n^{\prime}=2 w(-A \cos \alpha),
\end{aligned}
$$

and then

(41) $\quad h_{011}=\left\{\frac{1}{2 \pi} \int_{-\pi}^{\pi} 2 w(-A \cos \alpha) d \alpha\right\}^{2}=\left\{\frac{1}{\pi} \int_{-\pi}^{\pi} w(-A \cos \alpha) d \alpha\right\}^{2}$

$$
\begin{aligned}
& =\frac{1}{\pi^{2} \sigma_{1}^{2}}\left\{\frac{1}{\sqrt{2 \pi}} \int_{-\pi}^{\pi} \exp \left[-\frac{A^{2}}{2 \sigma_{1}^{2}} \cos ^{2} \alpha\right] d \alpha\right\}^{2}, \\
h_{022} & =0 \\
h_{111} & =0 \\
h_{122} & =\left\{\int_{-\infty}^{\infty} g_{1}^{(2)}\left(n^{\prime}\right) w\left(n^{\prime}\right) d n^{\prime}\right\}^{2} \\
& =\left\{\int_{-\infty}^{\infty} \frac{1}{2 \pi}\left[\int_{-\pi}^{\pi} g^{(2)}\left(n^{\prime}+A \cos \alpha\right) \cos \alpha d \alpha\right] w\left(n^{\prime}\right) d n^{\prime}\right\}^{2} \\
& =\left\{\frac{1}{2 \pi} \int_{-\pi}^{\pi}\left[\int_{-\infty}^{\infty} g^{(2)}\left(n^{\prime}+A \cos \alpha\right) w\left(n^{\prime}\right) d n^{\prime}\right] \cos \alpha d \alpha\right\}^{2} .
\end{aligned}
$$

Because

$$
\begin{aligned}
g^{(2)}\left(n^{\prime}+A \cos \alpha\right) & =2 \delta^{(1)}\left(n^{\prime}+A \cos \alpha\right) \\
\int_{-\infty}^{\infty} g^{(2)}\left(n^{\prime}+A \cos \alpha\right) w\left(n^{\prime}\right) d n^{\prime} & =2 \int_{-\infty}^{\infty} \delta^{(1)}\left(n^{\prime}+A \cos \alpha\right) w\left(n^{\prime}\right) d n^{\prime} \\
& =2(-1)^{1} w^{(1)}\left(n^{\prime}\right)
\end{aligned}
$$




$$
\begin{gathered}
\frac{d}{d n^{\prime}} w\left(n^{\prime}\right)=\frac{d}{d n^{\prime}} \frac{1}{\sqrt{2 \pi} \sigma_{1}} \exp \left[-\frac{n^{\prime 2}}{2 \sigma_{1}^{2}}\right]=-\frac{1}{\sqrt{2 \pi} \sigma_{1}} \frac{n^{\prime}}{\sigma_{1}^{2}} \exp \left[-\frac{n^{\prime 2}}{2 \sigma_{1}^{2}}\right], \\
w^{(1)}\left(n^{\prime}\right)=w^{(1)}(-A \cos \alpha)=\frac{A}{\sigma_{1}^{2}} \cos \alpha w(-A \cos \alpha),
\end{gathered}
$$

we have

$$
\begin{aligned}
h_{122} & =\left\{-\frac{1}{\pi} \int_{-\pi}^{\pi} \frac{A}{\sigma_{1}^{2}} \cos \alpha w(-A \cos \alpha) \cos \alpha d \alpha\right\}^{2} \\
& =\frac{A^{2}}{\pi^{2} \sigma_{1}^{6}}\left\{\frac{1}{\sqrt{2 \pi}} \int_{-\pi}^{\pi} \cos ^{2} \alpha \exp \left[-\frac{A^{2}}{2 \sigma_{1}^{2}} \cos ^{2} \alpha\right] d \alpha\right\}^{2}, \\
h_{211} & =\left\{\int_{-\infty}^{\infty} g_{2}^{(1)}\left(n^{\prime}\right) w\left(n^{\prime}\right) d n^{\prime}\right\}^{2} \\
& =\left\{\int_{-\infty}^{\infty} \frac{1}{2 \pi}\left[\int_{-\pi}^{\pi} g^{(1)}\left(n^{\prime}+A \cos \alpha\right) \cos 2 \alpha d \alpha\right] w\left(n^{\prime}\right) d n^{\prime}\right\}^{2} \\
& =\left\{\frac{1}{2 \pi} \int_{-\pi}^{\pi}\left[\int_{-\infty}^{\infty} g^{(1)}\left(n^{\prime}+A \cos \alpha\right) w\left(n^{\prime}\right) d n^{\prime}\right] \cos 2 \alpha d \alpha\right\}^{2} \\
& =\left\{\frac{1}{2 \pi} \int_{-\pi}^{\pi} 2 w(-A \cos \alpha) \cos 2 \alpha d \alpha\right\}^{2} \\
& =\frac{1}{\pi^{2} \sigma_{1}^{2}}\left\{\frac{1}{\sqrt{2 \pi}} \int_{-\pi}^{\pi} \cos 2 \alpha \exp \left[-\frac{A^{2}}{2 \sigma_{1}^{2}} \cos ^{2} \alpha\right] d \alpha\right\}^{2}, \\
h_{222} & =0 .
\end{aligned}
$$

We now determine the products $R_{s a}(\tau) R_{n^{\prime} \mu v}(\tau)$.

For $a=1$ and $\mu=\nu=2$, we have

$$
\begin{aligned}
R_{s 1}(\tau) R_{n^{\prime} 22}(\tau) & \\
= & \sum_{r=-\infty}^{\infty} J_{r}^{2}(D) \cos \left(\omega_{0}+r \omega_{m}\right) \tau \cdot \sigma_{1}^{4} \varrho^{2}(\tau)\left[1+\cos 2 \omega_{0} \tau\right] \\
= & \sum_{r=-\infty}^{\infty} \sigma_{1}^{4} \varrho^{2}(\tau) J_{r}^{2}(D) \cos \left(\omega_{0}+r \omega_{m}\right) \tau+ \\
& +\frac{1}{2} \sigma_{1}^{4} \varrho^{2}(\tau) \sum_{r=-\infty}^{\infty} J_{r}^{2}(D)\left[\cos \left(3 \omega_{0}+r \omega_{m}\right) \tau+\cos \left(\omega_{0}-r \omega_{m}\right) \tau\right] .
\end{aligned}
$$


For $a=2$ and $\mu=\nu=1$, we have

$$
\begin{aligned}
R_{s 2}(\tau) R_{n^{\prime} 11}(\tau) & \\
& =\sum_{r=-\infty}^{\infty} J_{r}^{2}(2 D) \cos \left(2 \omega_{0}+r \omega_{m}\right) \tau \cdot \sigma_{1}^{2} \varrho(\tau) \cos \omega_{0} \tau \\
& =\frac{1}{2} \sigma_{1}^{2} \varrho(\tau) \sum_{r=-\infty}^{\infty} J_{r}^{2}(2 D)\left[\cos \left(3 \omega_{0}+r \omega_{m}\right) \tau+\cos \left(\omega_{0}+r \omega_{m}\right) \tau\right]
\end{aligned}
$$

Due to the presence of band-pass filter at the amplitude limiter output, transferring frequencies in the neighbourhood of the frequency $\omega_{0}$, the following components will be used for the subsequent computation

$$
\begin{gathered}
R_{s 1}(\tau) R_{n^{\prime} 22}(\tau) \cong \sum_{r=-\infty}^{\infty} J_{r}^{2}(D) \sigma_{1}^{4} \varrho^{2}(\tau) \cos \left(\omega_{0}+r \omega_{m}\right) \tau+ \\
+\sum_{r=-\infty}^{\infty} J_{r}^{2}(D) \frac{\sigma_{1}^{4}}{2} \varrho^{2}(\tau) \cos \left(\omega_{0}-r \omega_{m}\right) \tau, \\
R_{82}(\tau) R_{n^{\prime} 11}(\tau) \approx \sum_{r=-\infty}^{\infty} J_{r}^{2}(2 D) \frac{\sigma_{1}^{2}}{2} \varrho(\tau) \cos \left(\omega_{0}+r \omega_{m}\right) \tau .
\end{gathered}
$$

Write

$$
\begin{gathered}
\frac{S_{i}}{N_{i}}=\frac{A^{2}}{2 \sigma_{1}^{2}}=p \\
\left\{\frac{1}{\sqrt{2 \pi}} \int_{-\pi}^{\pi} \exp \left[-p \cos ^{2} \alpha\right] d \alpha\right\}^{2}=C_{01}^{2}(p) \\
\left\{\frac{1}{\sqrt{2 \pi}} \int_{-\pi}^{\pi} \sin ^{2} \alpha \exp \left[-p \cos ^{2} \alpha\right] d \alpha\right\}^{2}=C_{10}^{2}(p) \\
\left\{\frac{1}{\sqrt{2 \pi}} \int_{-\pi}^{\pi} \cos ^{2} \alpha \exp \left[-p \cos ^{2} \alpha\right] d \alpha\right\}^{2}=C_{12}^{2}(p) \\
\left\{\frac{1}{\sqrt{2 \pi}} \int_{-\pi}^{\pi} \cos ^{\pi} 2 \alpha \exp \left[-p \cos ^{2} \alpha\right] d \alpha\right\}^{2}=C_{22}^{2}(p)
\end{gathered}
$$

The following approximate expression can be written for the correlation function at the output of the system: 


$$
\begin{aligned}
R_{y}(\tau) \cong \frac{4 p}{\pi^{2}} \sum_{r=-\infty}^{\infty} J_{r}^{2}(D) \cos \left(\omega_{0}+r \omega_{m}\right) \tau C_{10}^{2}(p)+ \\
+\frac{\varrho(\tau)}{\pi^{2}} \cos \omega_{0} \tau C_{01}^{2}(p)+\frac{\varrho^{2}(\tau)}{\pi^{2}} p \sum_{r=-\infty}^{\infty} J_{r}^{2}(D) \cos \left(\omega_{0}+r \omega_{m}\right) \tau C_{12}^{2}(p)+ \\
+\frac{\varrho^{2}(\tau) p}{2 \pi^{2}} \sum_{r=-\infty}^{\infty} J_{r}^{2}(D) \cos \left(\omega_{0}-r \omega_{m}\right) \tau C_{12}^{2}(p)+ \\
\quad+\frac{\varrho(\tau)}{\pi^{2}} \sum_{r=-\infty}^{\infty} J_{r}^{2}(2 D) \cos \left(\omega_{0}+r \omega_{m}\right) \tau C_{21}^{2}(p)
\end{aligned}
$$

3.5. Determination of the power of the useful signal and the power of the noise at the system output. The total power of the output signal $\boldsymbol{P}_{\text {out }}$ is determined by the relation

$$
\begin{aligned}
P_{\text {out }}=R_{y}(0) & =S_{0}(p)+N_{0}(p) \\
& \cong \frac{4}{\pi^{2}} p C_{10}^{2}(p)+\frac{1}{\pi^{2}} C_{01}^{2}(p)+\frac{3}{2 \pi^{2}} p C_{12}^{2}(p)+\frac{1}{\pi^{2}} C_{21}^{2}(p) .
\end{aligned}
$$

Quantity (45) has been found since

$$
\sum_{r=-\infty}^{\infty} J_{r}^{2}(a D)=1 \quad \text { and } \quad \varrho(0)=1 .
$$

The power of the useful signal $S_{0}(p)$, that of the noise $N_{0}(p)$, the ratio $S_{0}(p) / N_{0}(p)$ and the coefficient of improvement $\left(S_{0} / N_{0}\right) /\left(S_{i} / N_{i}\right)$ are determined in function of $p$ by the final relations

$$
\begin{aligned}
S_{0}(p) & =\frac{4}{\pi^{2}} p C_{10}^{2}(p) \\
N_{0}(p) & \cong \frac{1}{\pi^{2}}\left[C_{01}^{2}(p)+C_{21}^{2}(p)\right]+\frac{3}{2 \pi^{2}} p C_{12}^{2}(p) \\
\frac{S_{0}(p)}{N_{0}(p)} & =\frac{8 p C_{10}^{2}(p)}{2\left[C_{01}^{2}(p)+C_{21}^{2}(p)\right]+3 p C_{12}^{2}(p)} \\
\frac{S_{0}(p) / N_{0}(p)}{p} & =\frac{8 C_{10}^{2}(p)}{2\left[C_{01}^{2}(p)+C_{21}^{2}(p)\right]+3 p C_{12}^{2}(p)}
\end{aligned}
$$

3.6. Numerical computations. The numerical computation of the coefficients $C_{10}^{2}(p), C_{01}^{2}(p), C_{12}^{2}(p), C_{22}^{2}(p)$, as determined by equations (40)-(43) of the quantities $S_{0}(p), N_{0}(p), S_{0}(p) / N_{0}(p)$ and of the coefficient 
of improvement, has been performed on the ODRA 1204 digital computer. The results are represented in Table 1 and, graphically, in Figs. 3-5.

TABLE 1

\begin{tabular}{c|c|c|c|c}
\hline$p$ & $S_{0}$ & $N_{0}$ & $p_{0}=S_{0} / N_{0}$ & $p_{0} / p$ \\
\hline 0.01 & 0.006334 & 0.632649 & 0.0100 & 1.001 \\
0.02 & 0.012606 & 0.628694 & 0.0201 & 1.003 \\
0.05 & 0.031050 & 0.616931 & 0.0503 & 1.007 \\
0.08 & 0.048952 & 0.605325 & 0.8009 & 1.011 \\
0.10 & 0.060595 & 0.597679 & 0.1014 & 1.014 \\
0.20 & 0.115491 & 0.560599 & 0.2060 & 1.030 \\
0.50 & 0.251640 & 0.461776 & 0.5449 & 1.090 \\
0.80 & 0.354384 & 0.381570 & 0.9288 & 1.161 \\
1.00 & 0.408921 & 0.337451 & 1.2118 & 1.212 \\
2.00 & 0.577836 & 0.197367 & 2.9277 & 1.464 \\
5.00 & 0.723128 & 0.078402 & 9.2233 & 1.845 \\
8.00 & 0.757859 & 0.049145 & 15.4210 & 1.928 \\
10.00 & 0.768816 & 0.039477 & 19.4751 & 1.948 \\
20.00 & 0.790030 & 0.019971 & 39.5596 & 1.978 \\
50.00 & 0.802422 & 0.008056 & 99.6005 & 1.992 \\
80.00 & 0.805487 & 0.005047 & 159.6099 & 1.995 \\
100.00 & 0.806506 & 0.004040 & 199.6130 & 1.996
\end{tabular}

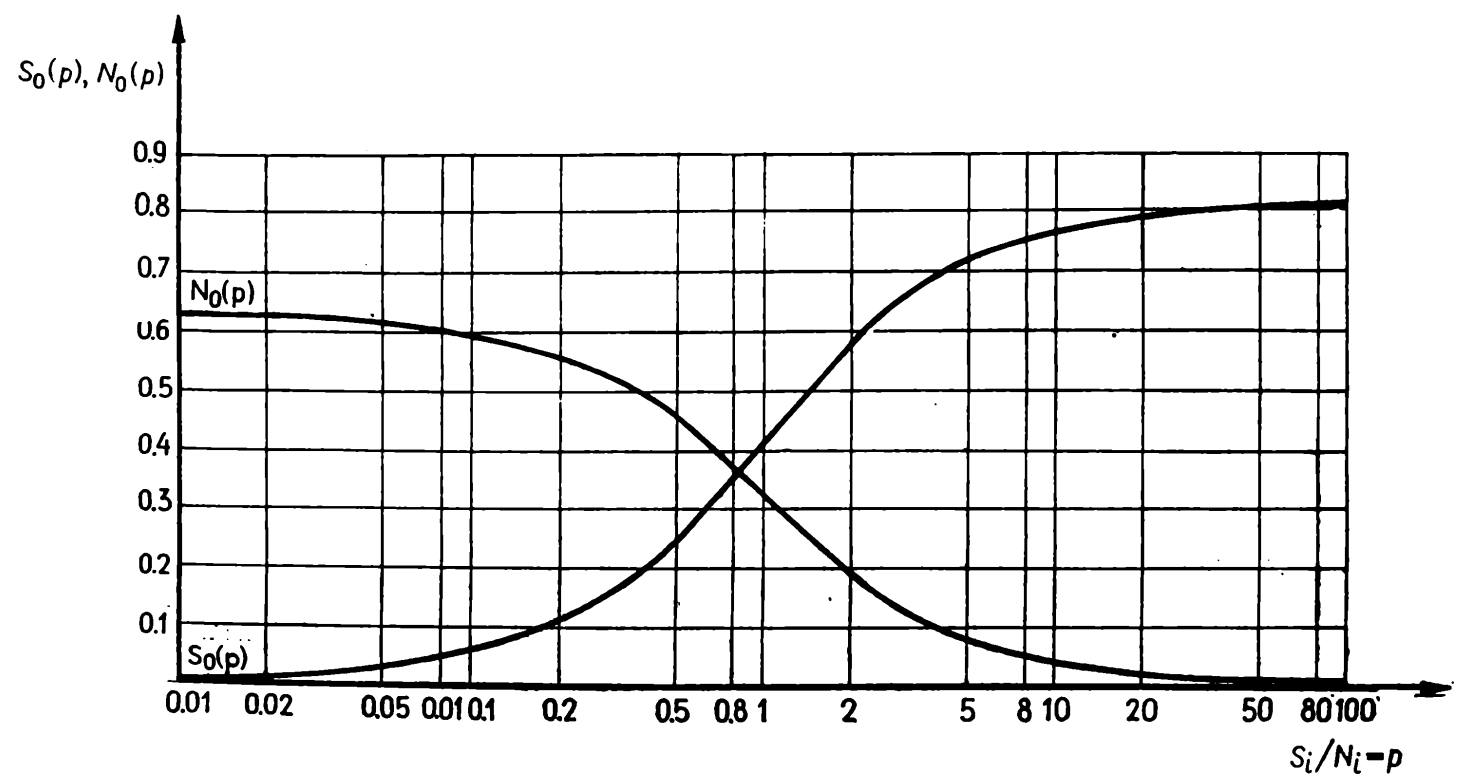

Fig. 3. Useful output signal power $S_{0}(p)$ and output noise power $N_{0}(p)$ of the amplitude limiter in function of the signal-to-noise power ratio $S_{i} / N_{i}$ at the input

It was assumed for computation that the value of the ratio $p=S_{i} / N$ of the power of the useful signal to the power of the noise at the input to the non-linear system varies within the limits from 0.01 to 100. This rang e of values for $\boldsymbol{p}$ is in accordance with practical needs. 


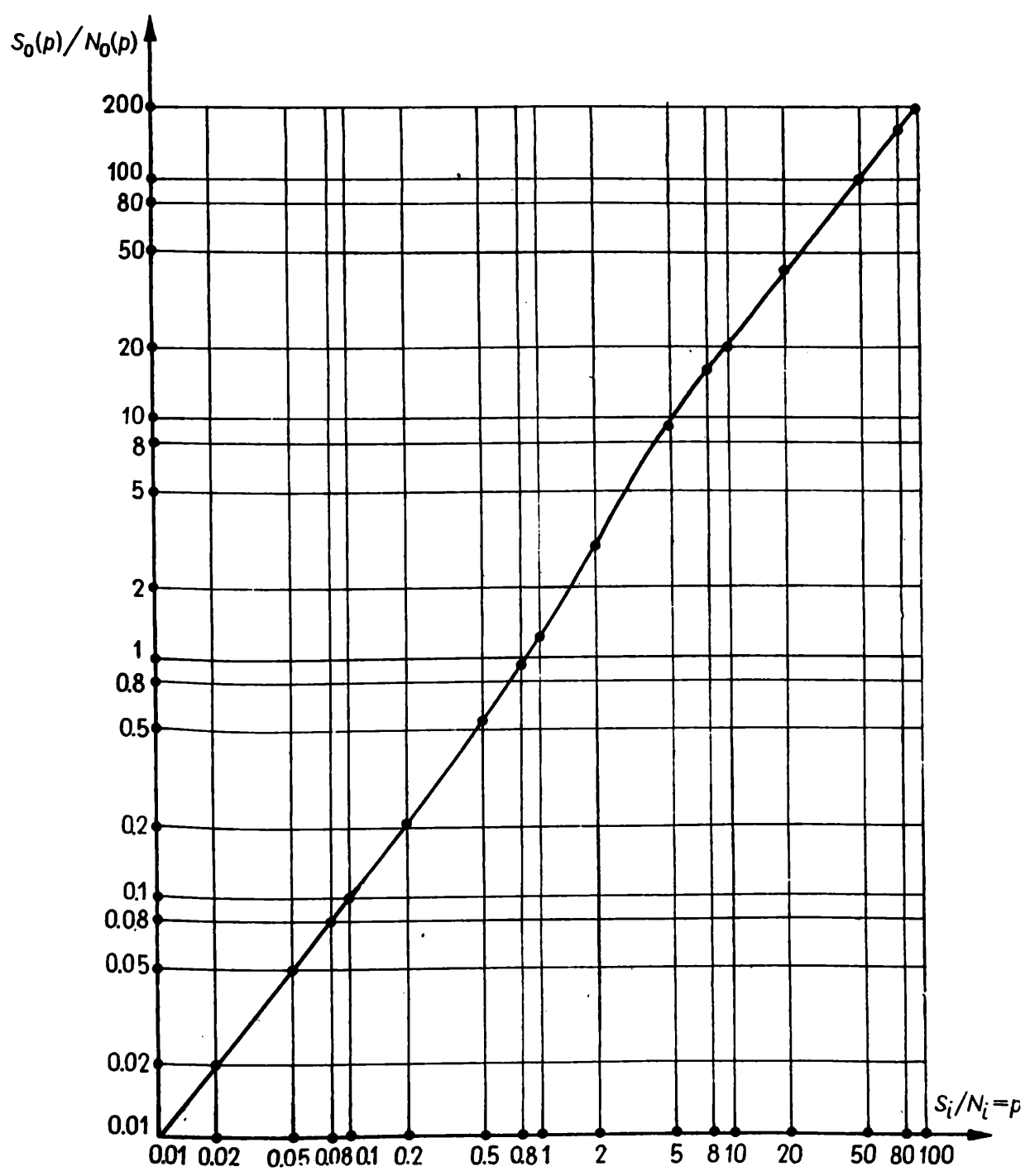

Fig. 4. Output signal-to-noise power ratio $S_{0}(p) / N_{0}(p)$ in function of the input signal-to-noise power ratio of the amplitude limiter

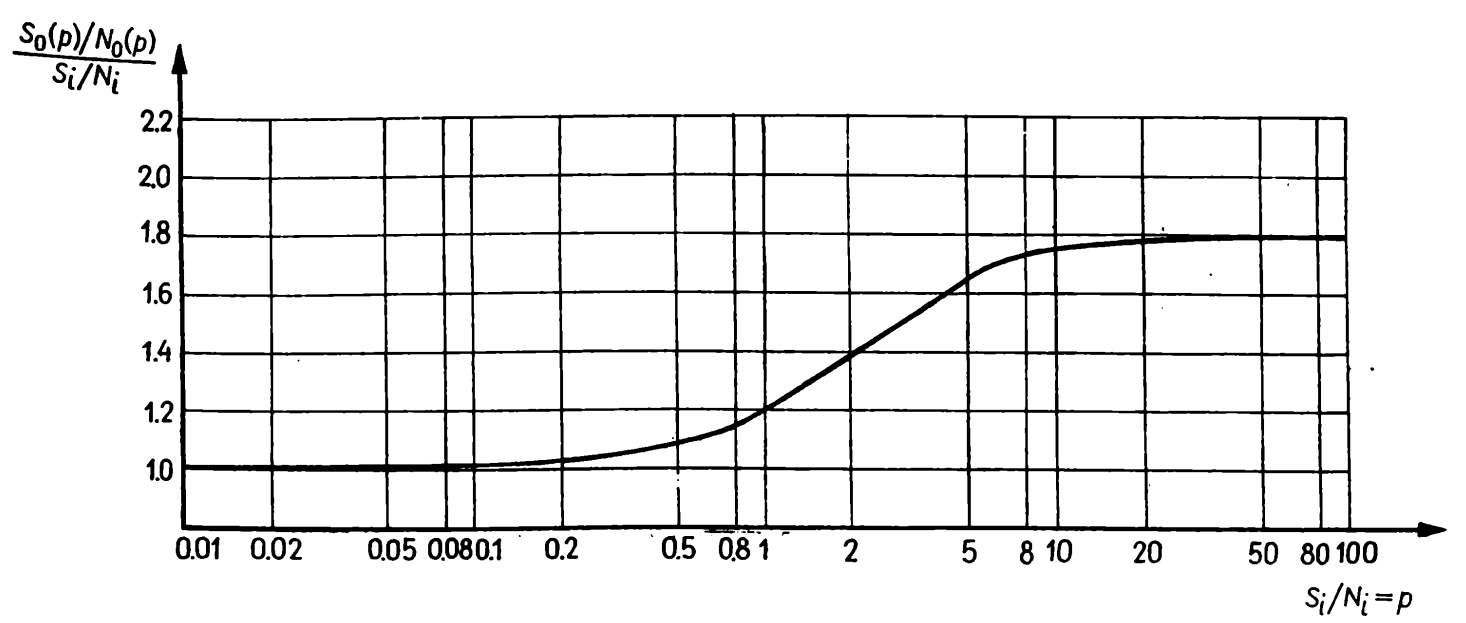

Fig. 5. The coefficient of improvement of the output signal-to-noise power ratio in function of the input signal-to-noise power ratio $S_{i} / N_{i}$ 


\section{CONCLUSIONS}

The general result obtained for the correlation functions and the spectrum of the output signal of the non-linear system, i.e. equation (34), has the form of a complicated series. However, the coefficients of that series can easily be computed. In practice, the result obtained can be used by confining ourselves to the numerical values of a few terms of the series, the coefficients of successive terms of the series decreasing rapidly.

The power of the output noise of the non-linear system is higher than that of the input noise. For the most effective separation of the useful signal from the noise one, it is necessary to provide at the output of the non-linear system a zonal filter of a frequency band just necessary for transmitting the useful signal without distortion. Such a zonal filter is used in the system analyzed in the present paper.

In view of the obtained numerical results, it can be stated that, for low values of the ratio $p=S_{i} / N_{i}$, the ratio of the corresponding values $S_{0} / N_{0}$ remains unchanged, that is, $\left(S_{0} / N_{0}\right) /\left(S_{i} / N_{i}\right) \approx 1$. For $p \geqslant 1$, there is an increase in $S_{0} / N_{0}$, and for $p \rightarrow \infty$ we have $\left(S_{0} / N_{0}\right) /\left(S_{i} / N_{i}\right) \rightarrow 2$. Thus, the system under consideration is seen to serve its principal purpose, of limiting the amplitude of the output signal, and does not essentially change the ratio of the power of the useful signal to that of the noise. The value of the coefficient of improvement is contained within the interval $[1,2]$.

The author wishes to express his gratitude to the thesis supervisor Dr. Jerzy Kucharczyk of the University of Wrocław. His assistance in the numerical computations necessary is also gratefully acknowledged

\section{References}

[1] W. B. Davenport, Signal-to-noise ratios in band-pass limiters, J. Appl. Physics 24 (1953), p. 720-727.

[2] - and W. L. Root, An introduction to the theory of random signals and noise, New York 1958.

[3] J. S. Gradstein and I. M. Ryzhik, Tables of integrals, sums, series and products, Moscow 1971.

[4] A. Papoulis, Probability, random variables and stochastic processes, McGraw-Hill, New York 1965.

[5] H. E. Rowe, Signals and noise in communication systems, Van Nostrand, Princeton, N. J., 1965.

[6] K. H. Schmelovsky, V. Kempe and J. Rienäcker, Probleme der Berechnung nichtlinearer Vierpole, die mit stochastischen Signalen beaufschlagt werden, Nachrichtentechnik 20 (1970), p. 47-50 and p. 92-102. 
[7] H. B. Shutterly, General results in the mathematical theory of random signals and noise in nonlinear devices, IEE Trans. Information Theory (1963), p. 74-84.

[8] W. J. Tikhonov, Statistical methods in radio engineering, Moscow 1966.

INSTITUTE OF CIVIL AERONAUTICS

WARSZAWA

Received on 22. 10. 1972

J. KAZMIERSKI (Warszawa)

NOWA METODA ANALIZY UKLADÓW NIELINIOWYCH

PRZY POBUdZaNiU SYGNAEAMI PRZYPADKoWYMI

I JEJ ZaStosowanie do ANALIZY OGRANICZNIKA AMPLITUdoWEgo

\section{STRESZCZENIE}

Treścią pracy jest obliczenie wartości mocy sygnału użytecznego $s_{0}$, mocy szumu zakłócającego $N_{0}$, stosunku $S_{0} / N_{0}$ oraz tzw. współczynnika poprawy $\left(S_{0} / N_{0}\right) /\left(S_{i} / N_{i}\right)$ na wyjściu układu nieliniowego, zwanego $\mathrm{w}$ radiotechnice idealnym ogranicznikiem amplitudowym, przy założeniu, że na jego wejście działają sygnał z modulacją częstotliwości o mocy $S_{i}$ i addytywny, niezależny do sygnału, biały szum gaussowski o mocy $N_{i}$. Dodatkowo przyjęto, że przed i za ogranicznikiem znajdują się układy liniowe o selektywnych charakterystykach częstotliwościowych, zwane filtrami pasmo. wymi.

Wartości mocy wyjściowych $S_{0}$ i $N_{0}$ obliczono pośrednio przez określenie w pierwszym kroku obliczeń funkcji korelacji dla sygnałów na wyjściu układu nieliniowego. Dla określenia funkcji korelacji zastosowano nową metodę, która polega na zastąpieniu wieloargumentowej funkcji charakterystycznej, występującej w wyrażeniu określającym funkcje korelacji, przez szereg funkcyjny. Wyrazy szeregu są określone przez momenty funkcji reprezentującej proces na wejściu układu nielinio. wego, a współczynniki przy wyrazach wyznaczone są przez całki oznaczone, w których integrandem sa iloczyny funkcji rozkładu gesstości prawdopodobieństwa procesu na wejściu i pochodne funkcji określającej nieliniowość badanego układu. Całki są łatwe do obliczenia dowolnymi metodami numerycznymi. Metoda ta była po raz pierwszy przedstawiona przez Shutterly'ego [7] i następnie rozwinięta przez Schmelowskiego i Kempego [6]. 